\title{
O.G. PENYAZKOV: ON THE OCCASION OF HIS 60TH BIRTHDAY
}

Oleg Glebovich Penyazkov, Editor-in-Chief of the Heat Transfer Research journal, Director of the State Scientific Institution "A.V. Luikov Heat and Mass Transfer Institute of the National Academy of Sciences of Belarus," Doctor of Physical and Mathematical Sciences, and Academician of the National Academy of Sciences of Belarus celebrates his 60th birthday on January 3, 2021.

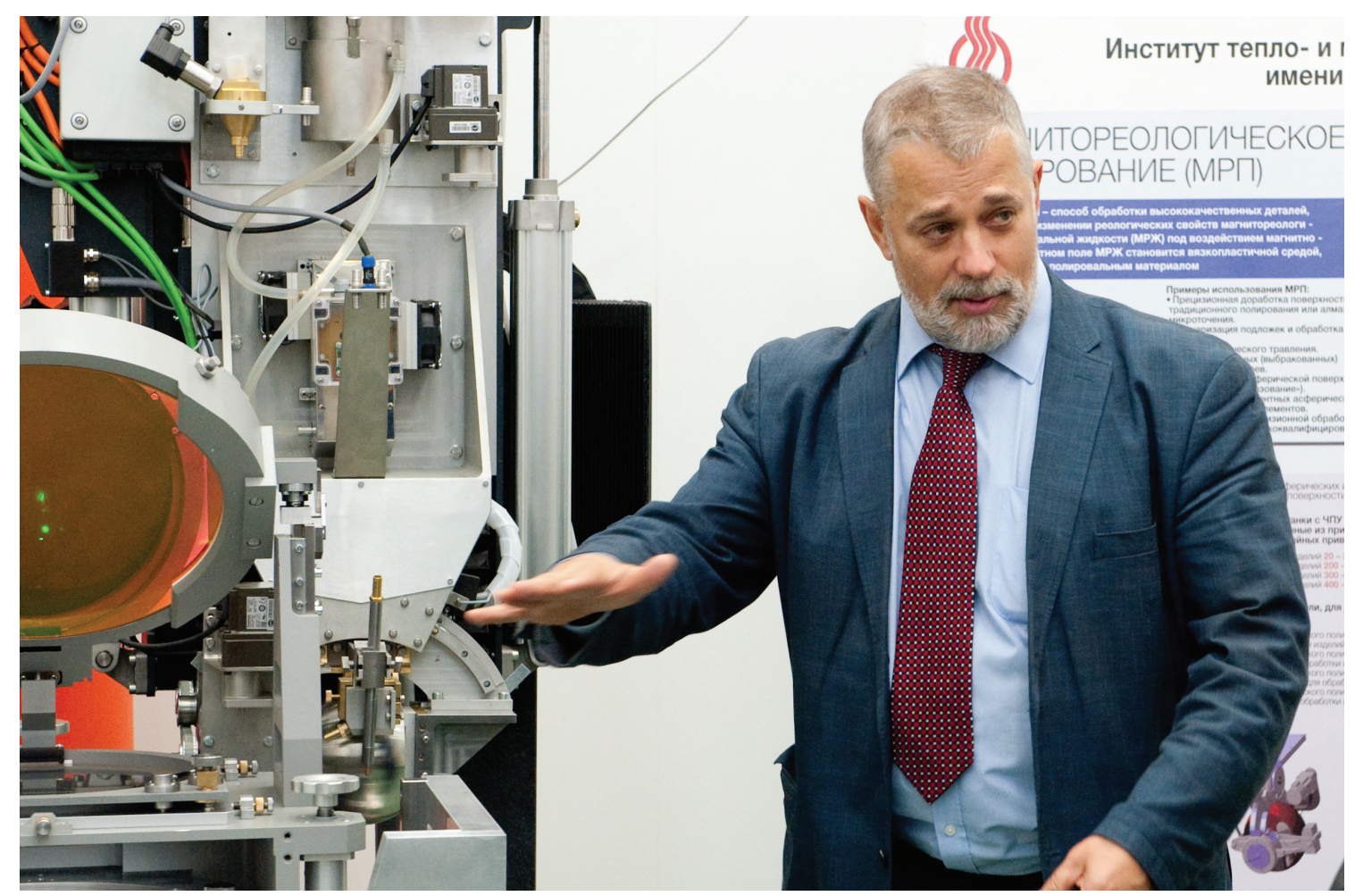

Being the youngest among the acting academicians of the National Academy of Sciences of Belarus, Prof. O.G. Penyazkov has gained international acceptance in scientific quarters due to his original experimental works in the field of high-temperature gas dynamics, physics of shock waves, combustion, explosion and detonation, and optical diagnostics of physicochemical processes.

The higher education on the basis of the Moscow Institute of Physics and Technology and Belarusian State University assigned his scientific route, which was begun by him in 1984 as a senior technician at the Heat and Mass Transfer Institute in Minsk. In 2011, O.G. Penyazkov was invited to become director of this institute, which is under his productive guidance for almost 10 years. He defended his doctoral thesis in 2004, in 2009 he was elected Corresponding Member of the National Academy of Sciences of Belarus, and in 2014, its Academician.

The active administrative work as the director of the institute and a member of some councils of experts O.G. Penyazkov combines successfully with his research work and with training highly skilled scientific personnel. Several candidates of sciences and doctors of sciences have been trained by him. Moreover, he is at the head of the Doctoral Dissertation Council.

O.G. Penyazkov is the author of 300 scientific works, including 6 monographs and is a constant reporting participant of various international symposia. At the beginning of the $2000 \mathrm{~s}$ he headed scientific-popular serial "Golden Section" at the Belarusian television, where his broad scientific knowledge and oratorical abilities were revealed in full measure. 
For the scientific successes achieved, development of international cooperation, contribution to the development and diversification of the export of science-intensive production O.G. Penyazkov was awarded a medal and premium of Academician V.A. Koptyug (Siberian Branch of the Russian Academy of Sciences), International Award and Medal of Academician A.V. Luikov (National Academy of Sciences of Belarus), a medal "For Merit" of the Federation of Russia's Astronautics for taking part in realization of space projects and programs, and a Professor Tsuoshi Asanuma medal for outstanding achievements in the field of flow visualization. O.G. Penyazkov was also awarded by a number of gratitude certificates and diplomas by various ministries and departments.

Due to his vigorous scientific activity and significant results obtained in studying the processes of combustion and gas detonation, O.G. Penyazkov was elected a member of the scientific societies of the International Combustion Institute and International Institute of Shock Waves, a member of the Council of Directors of the International Institute of the Dynamics of Explosions and Reacting Systems, International Center for Heat and Mass Transfer, and of the Italian Physical Society.

O.G. Penyazkov is Editor-in-Chief of two international journals: Heat Transfer Research (published by Begell House, USA) and Journal of Engineering Physics and Thermophysics (published by Springer) and takes part in the work of editorial boards of a number of home and foreign publications, heads the organizing committees of a number of republican and international specialized conferences, symposia, and forums.

As Director of the Heat and Mass Transfer Institute in Minsk O.G. Penyazkov has proved to be a talented organizer of science when he set going new research trends in the interests of the economy of the Republic of Belarus, as well as significant intensification of international cooperation. His administrative activity, scientific intuition, and strategic vision of the prospects of the development of the institute, under his supervision, made it possible to preserve, rejuvenate, and increase the personnel of the Institute, and significantly improve the scientific material-technical resources. Under the guidance of Academician O.G. Penyazkov, the Heat and Mass Transfer Institute stands at the front line and is considered to be one of the leading scientific organizations in the system of the National Academy of Sciences of Belarus, acknowledged internationally to be the center of heat and mass transfer studies.

Colleagues, students, friends, and the workers of the editorial offices of the Heat Transfer Research journal and of the Journal of Engineering Physics and Thermophysics heartily congratulate O.G. Penyazkov with his jubilee and wish him sound health and further successes and achievements! 